\title{
The Use of the Anterior Chamber Maintainer in Special Cataract Cases
}

\author{
Vasileios Lakidis", Antonios Lakidis ${ }^{2,3}$, Despoina Kolokotroni ${ }^{2}$, Diamantis Almaliotis ${ }^{2}$, \\ Vasileios Karampatakis ${ }^{2}$ \\ ${ }^{1}$ Bioclinic, Department of Ophthalmology, Thessaloniki, Greece; ${ }^{2}$ Laboratory of Experimental Ophthalmology Aristotle University \\ of Thessaloniki, Greece; ${ }^{3}$ The 1st Eye Clinic of AHEPA Hospital, Aristotle University of Thessaloniki, Greece. \\ Email: almaliotis_diamantis@yahoo.gr
}

Received July $11^{\text {th }}, 2012$; revised September $27^{\text {th }}, 2012$; accepted October $8^{\text {th }}, 2012$

\begin{abstract}
Purpose: To point out the indications for the use of the Anterior Chamber Maintainer (ACM) in order to facilitate cataract surgery in selective cases. Materials and Methods: In a time interval of 4 years the ACM was used in 28 special cataract cases 17 patients had high myopia (12 - $25 \mathrm{dpt}$, axial length $28-34 \mathrm{~mm}$ ), 3 patients had vitreo-retinal pathology known pre-operatively and 8 cases were previously vitrectomized with silicon oil. In these cases the ACM was introduced either from the beginning or during the surgical procedure when excessive fluctuations of the Anterior Chamber (AC) were observed. Results: Though the new generation phaco machines tend to maintain the stability of the AC, the use of the ACM contributed to even greater stability during the insertion and the removal of probes and during the whole procedure, eliminating the risk of complications. All these risky cases were accomplished without intraoperative complications. The surgeons experienced a sense of increased safety during the procedure. Conclusions: The use of the ACM in cataract cases with high risk for complications offers a much greater stability of the AC, by eliminating the fluctuations of the posterior capsule and consequently prevents intraoperative and potentially postoperative complications.
\end{abstract}

Keywords: ACM; Cataract Surgery; Intraoperative Complications

\section{Introduction}

The anterior segment surgeons very often have to manage special and difficult cataract cases. The use of the ACM stabilizes the intraocular presence during surgery [1] thus increasing safety in high risk cases Cataract surgeons have to be extra cautious when they manage eyes with high axial length. In high myopic eyes pathological degenerations of the sclera, choroid, retina and the vitreous often exist [2-6]. The most common type of cataract in high myopic eyes is the sub capsular cataract, which usually appears in younger ages and tends to progress rather fast [7]. Retinal degenerations of high myopic eyes are a risk factor of retinal detachment after cataract surgery and this fact is influenced by the age of the patient, the axial length of the eye, the pre-existence of retinal degenerations, history of retinal detachment surgery of the other eye, the surgical procedure and the integrity of the capsular bag [8-11]. In these cataract cases the rupture of the posterior capsule may have serious intra-operative and post-operative complications.

Another challenge for the surgeons of the anterior segment is the cataract surgery in previously vitrectomized eyes (pars plana vitrectomy). It is known that there is a higher rate of intra-operative and post-operative complications in those eyes. These complications occur due to the anatomical changes in the previously vitrectomized eyes, such as swallow anterior chamber, intra-operative miosis $[12,13]$, unstable posterior capsule [14], posterior capsule opacities [15], loose zonule and lack of support to the lens from the vitreous [16].

Despite all these difficulties, phaco surgery are considered safe and it is safer than the ECCE [17], however it is known that the use of an ACM increases the safety during anterior segment surgery [18].

The purpose of this report is to point out the indications of the use of the ACM in risky cataract cases so as to facilitate surgery and prevent complication.

\section{Material and Methods}

\subsection{Selection of Patients}

28 special cataract cases were operated by the use of an ACM.

Our material consisted of 28 eyes. 17 eyes had myopia 
higher than $12 \mathrm{dpt}(12$ - $25 \mathrm{dpt}$ and axial length 28 - 34 $\mathrm{mm}$ ), deep anterior chamber and some of them phacodonesis. 3 eyes had vitreo-retinal pathology (vitreo-retinal tractions such as diabetic retinopathy or retinal degenerations) known preoperatively and treated with prophylactic laser in the past and 8 eyes were previously vitrectomized and the vitreous cavity was filled with silicon oil.

The ACM was introduced, on the purpose to control the depth and the pressure in the anterior chamber when the phaco tip and the irrigation aspiration cannulas are inserted or removed from the eye during the procedure and also to keep the posterior capsule constantly far from the phaco tip minimizing the fluctuations.

\subsection{Surgical Procedure}

The Millennium from Bause and Lomb and the Infinity from Alcon Laboratories were used.

After the sterilization of the surgical field and topical anesthesia, 2 side ports were created at 3 and 9 o'clock for bimanual irrigation-aspiration and another corneal incision at a lower temporal position for the introduction of the ACM.

After the injection of the viscoelastic and the capsulorhexis, the ACM remained open at a height of about 60 $\mathrm{cm}$ from the eye.

The ACM remained open during the hydro-dissection, the phacoemulsification and the aspiration of cortex. After the aspiration of the cortical material the ACM flow was interrupted and viscoelastic was injected in the anterior chamber and the capsular bag for the insertion of the lens.

The aspiration of the viscoelastic was done with open flow of the ACM, even behind the IOL.

Every incision was carefully "sealed" by injecting BSS in the corneal stroma and the withdrawal of the ACM was done by simultaneous injection of BSS through a sideport.

The goal was to keep the AC as stable as possible during the procedure.

\section{Results}

In all these special cases, no intraoperative complications were observed, though according to the international literature and according to our experience high rates of complications are expected in such cases.

The intraoperative fluctuations of the anterior chamber and the surge phenomena were greatly eliminated.

No rupture of the posterior capsule occurred. In vitrectomized eyes with silicon oil the presence of the ACM prevented the invasion of silicon into the anterior chamber. The surgeons experienced an increased sense of safety during the procedure.

No postoperative cornea edema was observed. The IOP ranged within the expected normal values with no increase related to the surgery. There were no negative consequences on the expected final visual acuity. In a follow up period of 2 - 5 years, no clinical CME was detected and also retinal detachment did not occur in the eyes with high myopia and also in the eyes with known pre-existing retinal pathology (Table 1). All eyes were examined postoperatively for retinal pathology, and risk for retinal detachment and 3 more eyes were treated appropriately (with prophylactic laser) since a significant percentage of these eyes ( 5 eyes in the follow up period) required Nd:YAG capsulotomy postoperatively which may increase the risk of retinal detachment.

No silicon oil was detected in the anterior chamber in the vitrectomized eyes.

\section{Discussion}

The use of the ACM in our material contributed greatly to the success of phaco in special cataract cases such as in high myopic patients.

Alio et al. [19] reported that the possibility of retinal detachment in high myopic patients who underwent phaco was $2.7 \%$. Other researchers reported that the possibility of retinal detachment after phaco in myopic patients was quite higher $8 \%$ [20], and only $0.4 \%-1.2 \%$ of the general population that undergo phaco surgery [20].

In another study, Wilbrandt et al. [21] were the first who described the effects that take place during the phaco of high myopic cases thoroughly. They named these effects as LIRDS (lens-iris diaphragm retropulsion syndrome). It takes place during the insertion of the phaco tip in the eye and causes instant increase of the anterior chamber depth and dilation of the iris ("tomato-iris"). This phenomenon occurs due to the weight of the water column of the infusion. LIRDS usually rises in eyes with weak zonules pathology. They used an anterior chamber maintainer (Lewicky type) and lowered the height of the bottle in order to overcome this syndrome. The use of the $\mathrm{ACM}$ in our material stabilized the depth of the anterior chamber and undoubtedly was proved to be valuable for the safety of the procedure.

On the other hand, high ratio of complications is observed in previously vitrectomized eyes that undergo

Table 1. Pre-existing ocular pathology in 28 special cataract cases.

\begin{tabular}{cccc}
\hline $\begin{array}{c}\text { Number of } \\
\text { eyes }\end{array}$ & $\begin{array}{c}\text { Ocular } \\
\text { pathology }\end{array}$ & $\begin{array}{c}\text { Intraoperative } \\
\text { complications }\end{array}$ & $\begin{array}{c}\text { postoperative } \\
\text { complications }\end{array}$ \\
\hline 17 & $\begin{array}{c}\text { Myopia }(12-25 \mathrm{dpt}) \\
\text { Vitreo-retinal } \\
\text { pathology }\end{array}$ & No & No \\
3 & $\begin{array}{c}\text { Vitrectomized with } \\
\text { silicone }\end{array}$ & No & No \\
8 & & & No \\
\hline
\end{tabular}


phaco. Cole et al. [22] studied these complications. More specifically, in $12.5 \%$ rupture of the posterior capsule occurred, in $5.6 \%$ retinal detachment and in a few cases loss of vitreous and zonule rupture were recorded. Anatomical changes that take place after pars plana vitrectomy prejudice the onset of complications. Yung et al. [23] investigated the pathophysiological changes that occurred in eyes that underwent vitrectomy and admission of silicon oil. A hypertrophic response of the anterior capsule of about $20-25 \mu \mathrm{m}$ was observed. Also, the epithelium of the lens was hypertrophic and fibrosis of the posterior surface of the anterior capsule occurred. These changes make the work of the cataract surgeon really difficult in relation to the posterior capsule fluctuations as a result of the lack of support due to the previous vitrectomy. The role of the ACM in previously vitrectomized eyes, with silicon oil is really of significant importance. It is wellknown that during phaco, when the phaco tip is removed, silicon oil pervade through zonule to the anterior chamber. More specifically, the intraocular pressure drops significantly when the phaco tip is removed from the eye. Due to the collapses of the anterior chamber, the iris diaphragm is protruded and the zonular spaces become wider. Through these spaces silicon oil drops, pass into the anterior chamber. The ACM in our cases, stabilized the intraocular pressure and thus prevented the passage of the silicon oil to the anterior chamber.

Furthermore, the ACM, due to the stability of the depth of the anterior chamber, diminishes the vitreo-retinal tractions in pathological cases such as proliferative diabetic retinopathy. Some researchers [24] tried to eliminate these vitreo-retinal tractions, in patients with diabetic retinopathy, with the use of intravitreal injections of bevanizumab. They aimed at reducing the proliferative neovascularisation, the edema and the tractions between the vitreous and the retina. ACM is obviously useful in these cataract cases.

Another application of the ACM is in cases of rupture of the anterior capsule (capsulorhexis tear). In our opinion (experience in a great number of phaco cases), the application of the ACM stabilizes the pressure in the anterior chamber and it may prevent the extension of the rupture to the posterior capsule.

Other researchers [25] investigated the vitreous loss that is observed in cases of rupture of the posterior capsule during phaco. They compared cataract cases that were performed by experienced surgeons with or without the ACM. They concluded that both groups had the same percentage of post-operative complications and also a greater vitreous loss was observed when the rupture of the posterior capsule occurred with the presence of an ACM. In our material no capsule rupture occurred.

It also has to be mentioned that complicated cataract surgery is related with higher incidence of CME. It has to be outpointed that none of our patients developed clinical CME.

Conclusively, according to our experience, the use of an ACM facilitates the operation and makes surgeon feel safer. It increases the safety of the phaco procedure by increasing the stability of the depth of the anterior chamber and by reducing the posterior capsule fluctuations during the insertion and withdrawal of the phaco tip and the irrigation aspiration cannulas. Thus many intra-operative and postoperative complications may be prevented.

\section{REFERENCES}

[1] M. Blumenthal, E. L. Assia, V. Chen and I. Anvi, "Using an Anterior Chamber Maintainer to Control Ointraocular Pressure during Phacoemulsificatio," Journal of Cataract \& Refractive Surgery, Vol. 20, No. 1, 1994, pp. 93-96.

[2] J. L. Alio, J. M Ruiz-Monero, et al., "The Risk of Retinal Detachment in High Myopia after Small Incision Coaxial Phacoemulsification," American Journal of Ophthalmology, Vol. 144, No. 1, 2007, pp. 93-98.

doi:10.1016/j.ajo.2007.03.043

[3] S. P. Percival, "Redefinition of High Myopia: The Relationship of Axial Length Measurement to Myopic Pathology and Its Relevance to Cataract Surgery," Developments in Ophthalmology, Vol. 14, 1987, pp. 42-46.

[4] H. Mondon and P. Metge, "Définitions: La Myopie Forte Masson," Paris, 1994.

[5] L. Buratto, Le. Burato and C. Burato, "Phacoemulsification of the Cataract in Severe Myopia," In: L. Buratto, R. H. Osher and S. Masket, Eds., Cataract Surgery in Complicated Cases, Thorofare, New Jersey, SLACK Inc., 2000, pp. 49-63.

[6] P. S. Koch, "Phacoemulsification in Patients with High Myopia," In: L. W. Lu and I. H. Fine, Eds., Phacoemulsification in Difficult and Challenging Cases, Thieme Medical Publishers, Inc., New York, 1999, pp. 13-20.

[7] R. de Natale, G. Romeo, F. Fama and L. Scullica, "Humans Lens Transparence in High-Myopic Subjects," Ophthalmologica, Vol. 205, No. 1, 1992, pp. 7-9. doi:10.1159/000310303

[8] L. Fernadez-Vega, J. Alfonso and T. Villacampa, "Clear Lens Extraction for the Correction of High Myopia," Ophthalmology, Vol. 110, No. 12, 2003, pp. 2349-2353. doi:10.1016/S0161-6420(03)00794-2

[9] A. Kubaloglou, T. Yazicioglu and S. Tacer, "Small Incision Clear Lens Extraction for the Correction of High Myopia," European Journal of Ophthalmology, Vol. 14, No. 1, 2004, pp. 1-6.

[10] G. Ripandelli, C. Scassa, V. Parisis, et al., "Cataract Surgery as a Risk Factor for Retinal Detachment in Very Highly Myopic Eyes," Ophthalmology, Vol. 110, No. 12, 2003, pp. 2355-2361. doi:10.1016/S0161-6420(03)00819-4

[11] J. Colin, A. Robinet and B. Cochener, "Retinal Detachment after Clear Lens Extraction for High Myopia," Ophthalmology, Vol. 106, No. 12, 1999, pp. 2281-2285. 


\section{doi:10.1016/S0161-6420(99)90526-2}

[12] M. A. Shousa and S. H. Yoo, "Cataract Surgery after Pars Plana Vitrectomy," Current Opinion in Ophthalmology, Vol. 21, No. 1, 2010, pp. 45-49. doi:10.1097/ICU.0b013e32833303bf

[13] S. M. Pinter and A. Sugar. "Phacoemulsification in Eyes with Past Pars Plana Vitrectomy: Case-Control Study," Journal of Cataract \& Refractive Surgery, Vol. 25, No. 4, 1999 , pp. 556-561.

[14] F. H. Koch, A. Cusumano, P. Seifert, et al., "Ultrastructure of the Anterior Lens Capsule after Vitrectomy with Silicone Oil Injection. Correlation of Clinical and Morphological Features," Documenta Ophthalmologica, Vol. 91, No. 3, 1995, pp. 233-242. doi:10.1007/BF01204174

[15] A. Akinci, C. Batman and O. Zileilioglou. "Cataract Surgery in Previously Vitrectomized Eyes," International Journal of Clinical Practice, Vol. 62, No. 5, 2008, pp. 770775. doi:10.1111/j.1742-1241.2007.01281.x

[16] W. E. Smiddy, W. J. Stark, R. G. Michels, et al., "Cataract Extraction after Vitrectomy," Ophthalmology, Vol. 94, No. 5, 1987, pp. 483-487.

[17] Z. Biro and B. Kovacs, "Results of Cataract Surgery in Previously Vitrectomized Eyes," Journal of Cataract \& Refractive Surgery, Vol. 28, No. 6, 2002, pp. 1003-1006. doi:10.1016/S0886-3350(02)01237-3

[18] H. B. Chawla and A. D. Adams, "Use of the Anterior Chamber Maintainer in Anterior Segment Surgery," Journal of Cataract \& Refractive Surgery, Vol. 22, No. 2, 1996, pp. 172-177.

[19] J. L. Alio, J. M. Ruiz-Moreno, M. H. Shabayek, F. L. Lugo and A. M. Abd el Rahman, "The Risk of Retinal Detachment in High Myopia after Small Incision Coaxial Phacoemulsification," American Journal of Ophthalmo- logy, Vol. 144, No. 1, 2007, pp. 93-97. doi:10.1016/j.ajo.2007.03.043

[20] M. Russel, B. Gaskin, D. Russel and P. J. Polkinghorne, "Pseudophakic Retinal Detachment after Phacoemulsification Cataract Surgery: Ten-Year Retrospective Review," Journal of Cataract \& Refractive Surgery, Vol. 32, No. 3, 2006, pp. 442-445. doi:10.1016/j.jcrs.2005.12.095

[21] H. R. Wilbrandt and T. H. Wilbrandt, "Pathogenesis and Management of the Lens-Iris Diaphragm Retropulsion Syndrome during Phacoemulsification," Journal of Cataract \& Refractive Surgery, Vol. 20, No. 1, 1994, pp. 48-53.

[22] C. J. Cole and D. G. Charteris, "Cataract Extraction after Retinal Detachment Repair by Vitrectomy: Visual Outcome and Complications," Eye (Lond), Vol. 23, No. 6, 2009, pp. 1377-1381. doi:10.1038/eye.2008.255

[23] C. W. Yung, A. Oliver, J. M. Bonnin and H. Gao, "Modified Anterior Capsulotomy Technique and Histopathology of the Anterior Capsule in Cataracts after Prolonged Exposure to Intravitreal Silicone Oil," Journal of Cataract \& Refractive Surgery, Vol. 34, 2008, pp. 2020-2023. doi:10.1016/i.jcrs.2008.06.050

[24] A. Akinci, C. Batman, E. Ozkilic and A. Altinsoy, "Phacoemulsification with Intravitreal Bevacizumab Injection in Diabetic Patients with Macular Edema and Cataract," Retina, Vol. 29, No. 10, 2009, pp. 1432-1435. doi:10.1097/IAE.0b013e3181b77422

[25] S. Androudi, P. Brazitikos, N. T. Papadopoulos, D. Dereklis, S. Lake and N. Stangos. "Posterior Capsule Rupture and Vitreous Loss during Phacoemulsification with or without the Use of an Anterior Chamber Maintainer," Journal of Cataract \& Refractive Surgery, Vol. 30, No. 2, 2004, pp. 449-452. doi:10.1016/S0886-3350(03)00584-4 